\title{
Improving Cognitive Decision-Making into Adaptive Educational Systems through a Diagnosis Tool based on the Competency Approach
}

\author{
https://doi.org/10.3991/ijet.v14i07.9870 \\ Najoua Hrich ${ }^{(凶)}$, Mohamed Lazaar, Mohamed Khaldi \\ Abdelmalek Essaâdi University, Tetouan, Morocco \\ amine.najoua@gmail.com
}

\begin{abstract}
Adaptive Educational systems (AES) does not necessarily lead to a better learning. Several kinds of research reveal that the problem is due to, on the one hand, the accent is put mainly on the technological tools to the detriment of the pedagogical aspect. On the other hand, there is a lack of the importance given to the assessment which is an integral part of the learningteaching process and the professional act of primary importance which gives the decisions and the consequences that result from it.In this paper, we propose a solution for the diagnostic evaluation based on competency approach especially on the pedagogy of integration. The proposed solution allows getting information about the available learners' knowledge level by presenting an assessment based on the common definition given to competencies by the majority of the authors of the domain. In this context, the assessment process proposed is presented on two steps: the first step, we evaluate resources related to the competence to verify their acquisition degree and to remediate if necessary, the second step will evaluate the capacity of leaner to mobilize those resources in order to apprehend a situation and respond to it in a more or less relevant way. This research aims to present a new vision in the context of the assessment into adaptive educational systems.
\end{abstract}

Keywords-Assessment process, competencies, ontologies, the pedagogy of integration, adaptive educational systems, knowledge level, learning style.

\section{Introduction}

Adaptive Hypermedia Educational systems (AHES) inspect learners 'characteristics and make appropriate adjustments to support learning. The main goal of AHES is to flexible environment that supports learning for students with a range of abilities, disabilities, interests, backgrounds, and other characteristics. The challenge of accomplishing this goal depends largely on accurately identifying characteristics of a particular learner or group of learners - such as type and level of knowledge, skills, personality traits, affective states - and then determining how to leverage the information to improve student learning [6-8]. 
In AHES, the form of a user knowledge model is the scalar model, which estimates the level of user domain knowledge by a single value on some scale - quantitative (a number ranging from 0 to 5) or qualitative (good, average, poor, none).Scalar models, especially qualitative, are quite similar to stereotype models. The difference is that scalar knowledge models focus exclusively on user knowledge and are typically produced by user self-evaluation. Despite their simplicity, scalar models can be used effectively to support simple adaptation techniques in AHES. These systems divide their users into two or three classes according to their knowledge level of the subject (i.e., expert, intermediate, and novice) and serve different versions of the whole page content or page fragments to learners with different levels of knowledge. [8]

In other words, the results of a diagnostic or formative assessment are translated by an affectation of a learner cognitive profile according to a score. Learners who had the same score have the same cognitive profile and also the same remedial activities. In this case, learners who have the same score, even if they have different learning deficiencies, get the same remediation since the score brings the same information; and it is here where resides the whole problem of the adaptation in terms of the remedial activities' content.

Although, Evaluation has to improve the learning process, by providing an efficient diagnostic, to identify learning difficulties, in order to precise the real knowledge level, and this latter is one of the several important factors to be considered by designers of adaptive educational systems; This article describes the design of an assessment process into an AHES which gives more importance in the specification of learners 'needs.

Our proposition is based on the competency approach and on the pedagogy of integration to specify - for an evaluated competency- the acquired \& the non-acquired resources and then the capacity of their mobilization to apprehend a situation and to resolve it in a more or less relevant way.

This contribution presents a continuity of our previous work [9-11], and aims to define the knowledge level of learner in a reliable and valid way: It aims to diagnose effectively the learners' needs and use that information to build a dynamic profile for each learner and leverage an appropriate support.

\section{Theoretical Foundation and Adopted Approaches}

\subsection{Presentation of a competency}

Most authors today tend to agree on the definition of a competence as the spontaneous mobilization of a set of resources in order to apprehend a situation and respond to it in a more or less relevant way [12-17]. Based on this definition, we can present the competence as (figure1): 


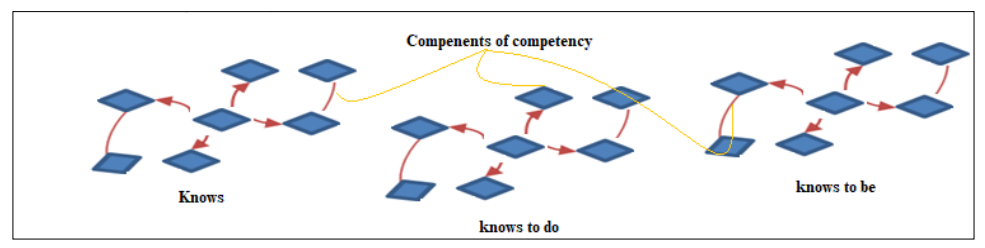

Fig. 1. Competency Components

\subsection{The conception of learning activities according to the pedagogy of integration [18]}

In the competency approach, there are essentially two moments in learning: Specific learning of resources: resources are the subject of specific learning, and it is a priority to develop competency resources. -Integration activities and formative evaluation: The second part of learning time is reserved for what we call "integration activities", it is dedicated to teaching the learner to mobilize his resources in complex situations. This integration can be done gradually, or at once, in an important module, called "integration module".

As example, we represent a competency which requires the development of 7 specific objectives, or resources. Integration can be achieved in two ways.

Progressively: During the learning (table1)

Table 1. Progressive integration

\begin{tabular}{|l|l|l|c|c|c|c|c|c|c|}
\hline Obj1 & Obj2 & & Obj3 & Obj4 & & Obj5 & Obj6 & Obj7 & $\begin{array}{c}\text { Integration } \\
\text { Module }\end{array}$ \\
\hline
\end{tabular}

At the end of learning (table2)

Table 2. Integration at the end of learning

\begin{tabular}{|c|c|c|c|c|c|c|c|}
\hline Obj1 & Obj2 & Obj3 & Obj4 & Obj5 & Obj6 & Obj7 & Integration Module \\
\hline
\end{tabular}

The first way proceeds by progressive integration. It is richer, but it is not always possible.

The integration module is followed by a formative assessment module. To conduct the formative assessment, a family of complex situations related to a competency is presented to the learners.

\subsection{Competency assessment}

Whatever is their reference frame, anyone who inscribes their reflection, or their pedagogical practice, in the competency-based approach agree today that they are exercised when it is a question to solving problem situations requiring the 
mobilization of several resources. Whether it is for the learning competencies or for their evaluation, it is thus advisable to place the learner in a complex environment and to require from him the mobilization of its various resources to solve a complex situation.

The purpose of a competency assessment is to assess the learner's ability to mobilize a set of internal and external resources through complex tasks called an assessment situation. This approach can be applied in the context of a summative evaluation which takes place at the end of a learning for certification purposes. If a learner does not succeed in this evaluation, the adoption of this approach does not allow to specify its difficulties, its strengths and even the component responsible for this failure.

To overcome this limitation, we opt in our diagnostic tool for a competency assessment on two phases as it's represented in figure2.

\begin{tabular}{|c|l|}
\hline Phasel & $\begin{array}{l}\text { Specific validation of the } \\
\text { resources, phase which } \\
\text { allows ensuring the } \\
\text { acquisition of each } \\
\text { resource }\end{array}$ \\
Phase2 & $\begin{array}{l}\text { after validation of the } \\
\text { acquisition of the } \\
\text { resources, the learner is led } \\
\text { to mobilize his acquired } \\
\text { resources }\end{array}$ \\
$\begin{array}{l}\text { Assessment of the capacity } \\
\text { of resources' mobilization }\end{array}$
\end{tabular}

Fig. 2. E-assessment based on competency approach

\section{Proposed Diagnostic Tool}

\subsection{Pedagogical apport}

In most educational systems, learners use tutoring sessions to prepare for exams or competitions. After completion of a learning module, either face-to-face or online, learners use tutoring sessions to overcome their difficulties or to consolidate their learning.

In order to achieve the objectives envisaged by the tutoring, our proposed tool is used to specify in an efficient manner the needs of each learner and select the appropriate content' remediation.

After determining the appropriate content of the remediation activity, in terms of resources and their mobilization, the activity will be presented according to its learning style (using a measuring instrument). With those characteristics, this tool allows to improve the learning-teaching process in different ways:

- For the learner: Being exposed to a content that suits his profile and that targets the knowledge he lacks, by using an optimal pedagogical approach that keeps the 
learner in his proximal development zone $(\mathrm{PDZ})^{1}$, he is more likely to perceive his learning as relevant and challenged and he focuses on notions he does not master and he devotes all his energy to the learning he needs.

- For the tutor/teacher: The tool provides precious information that allows him to identify what knowledge and skills he would develop with his learners. Thanks to the collected data, this tool allows him to know if the invested efforts in training report as desired or it is necessary to adjust the shot.

- The proposal diagnostic tool is to use in the context of supporting at the tutoring session that means learners who use it are already did and finished their learning sessions, the objective is to support and respond to their specific needs:

\subsection{Overview of assessment ontology}

In the classical assessment approach, the questions cover the whole of a module, unit, chapter or lesson according to the object of assessment. But there are no links between the questions and specific concepts to evaluate. The presentation of relations between specific concepts allows having more indicators and information about their acquisition degree.

To represent the relationship between those elements, we adopt, in our approach, the semantic web ontologies by the advantages they offer in terms of complete and semantic formalization of information. For this, we have conceived a competency assessment ontology which aims to represent the evaluation of a competence under an interoperable form to guarantee its reuse and sharing between different learning platforms.

Our ontology describes relations between the competencies 'component, questions and the objects to evaluate. So, to validate a specific concept, the learner must answer the questions related to this concept and concepts in relation with, which leads to a more relevant evaluation. (figure3)

Vygotsky introduce the PDZ as "the distance between the actual developmental level as determined by independent problem solving and the level of potential development as determined through problem solving under adult guidance, or in collaboration with more capable peers".

\footnotetext{
${ }^{1}$ Vygotsky introduce the PDZ as "the distance between the actual developmental level as determined by independent problem solving and the level of potential development as determined through problem solving under adult guidance, or in collaboration with more capable peers".
} 


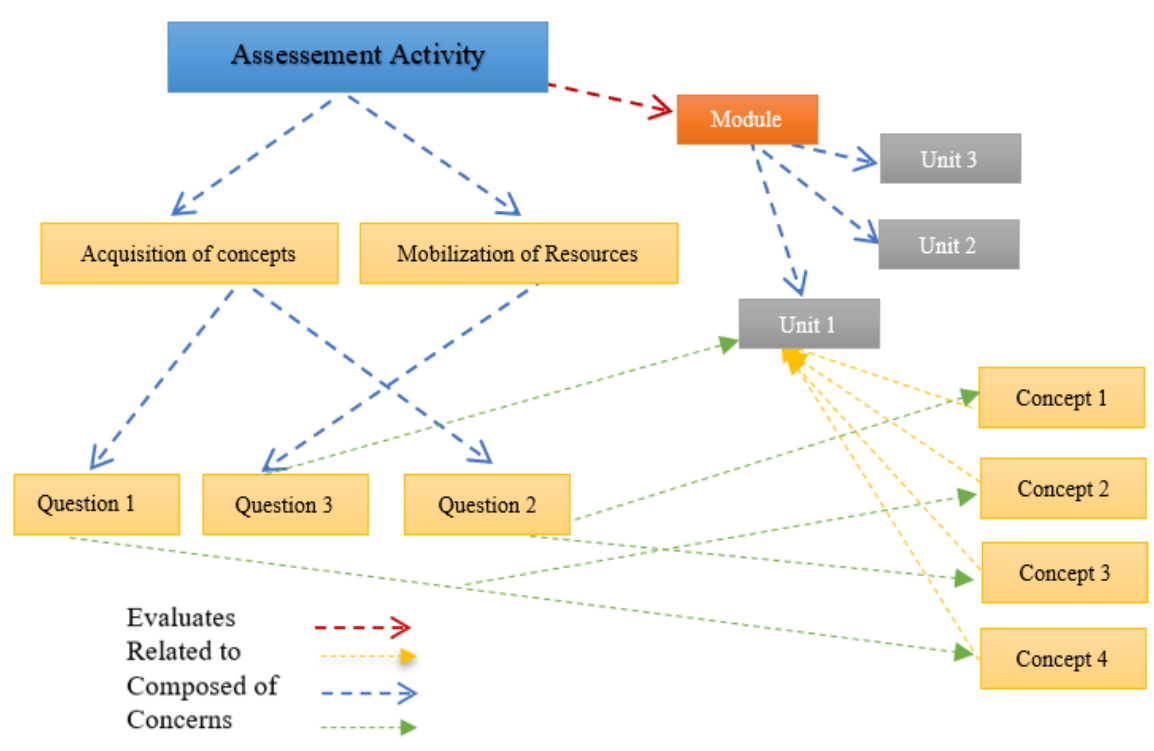

Fig. 3. E-Assessment Ontology

\subsection{Algorithm for a specific competency assessment}

By adopting the competency approach, there are essentially two moments in learning:

- Specific learning of resources: resources are the subject of specific learning, and it is a priority to develop competency resources.

- Integration activities and formative evaluation: The second part of learning time is reserved for what it calls "integration activities", it is dedicated to teaching the learner to mobilize his resources in complex situations. This integration can be done gradually, or at once, in an important module, called "integration module.

From this optic, our approach consists oDf treating each component of competence as a separate entity; each component is evaluated and supported if necessary. Then we go on to assess the mobilization of those components in an integration module as it represented in table 3 .

Table 3. Assessment timeline

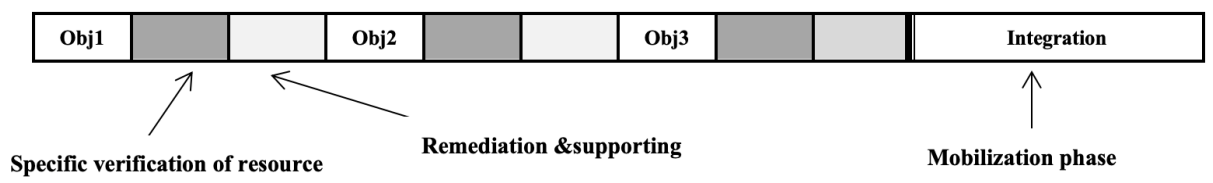


Based on what is already presened, the assessment process adopted in our approach is represented in figure 4.

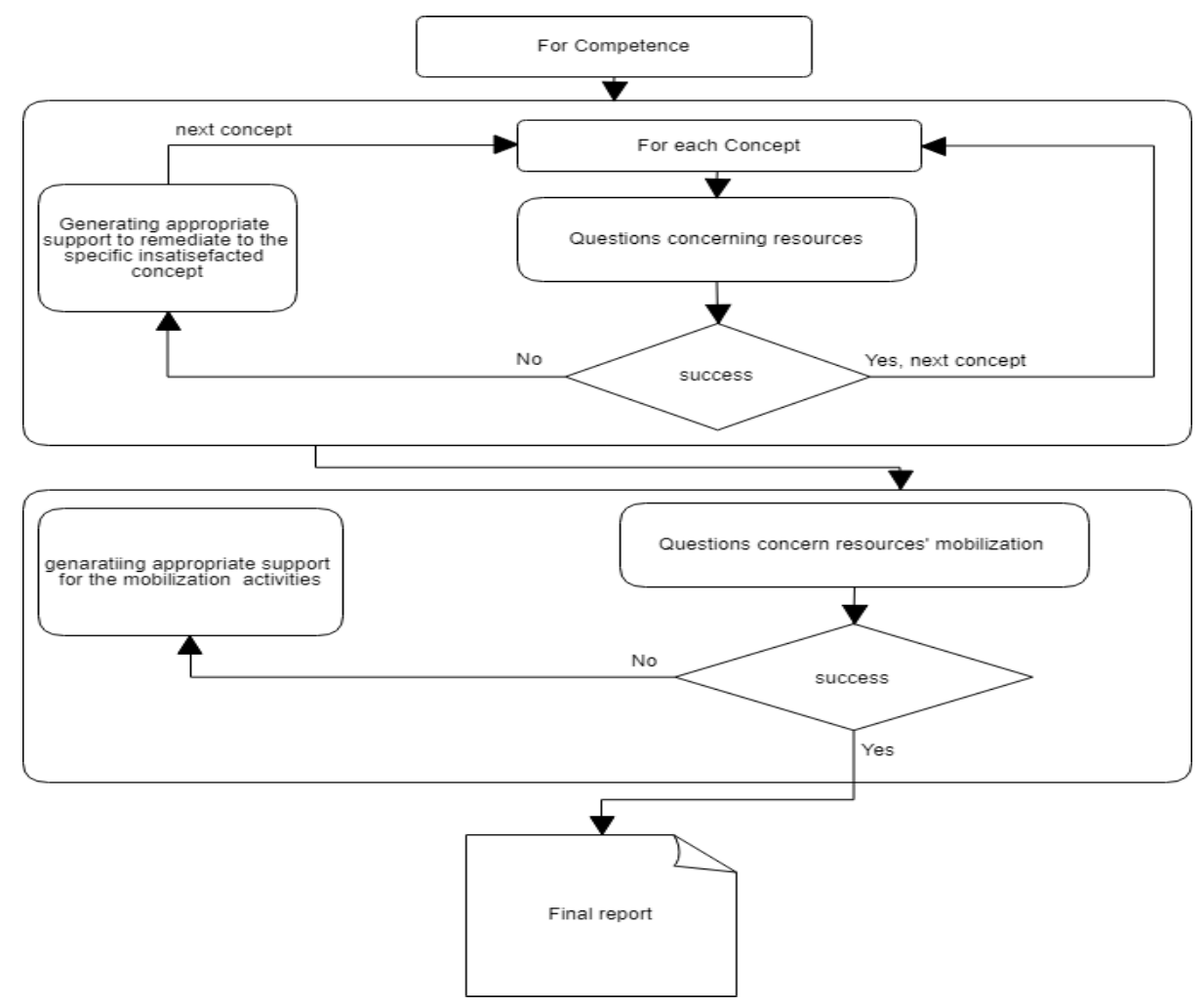

Fig. 4. E-Assessment Process

At the end of the process, a final report will be generated, containing information about the learner 'progression, learning2 path adopted and more relevant information which will be very useful for the learner, for the teacher and can be reused by the system for next users (to adopt same supporting for other learners with the same initial state).

\section{Integration Into An AEHS}

\subsection{Architecture of AEHS}

In general, the architecture of educational adaptive systems (AEHS) comprises two layers: the storage and execution layer.

The storage layer is the main engine that controls the adaptive process whose main tasks are: 
- Initialization and update of the learner model

- The choice of domain model concepts, learning resources by applying specific rules.

- Storing the learning resources, domain ontologies, the model of the learner, etc.

The execution layer is responsible for the presentation of the adaptive learning material to the user and the observation of the user's actions so as to update the learner model.

Figure 4 represents the architecture of AEHS [19]

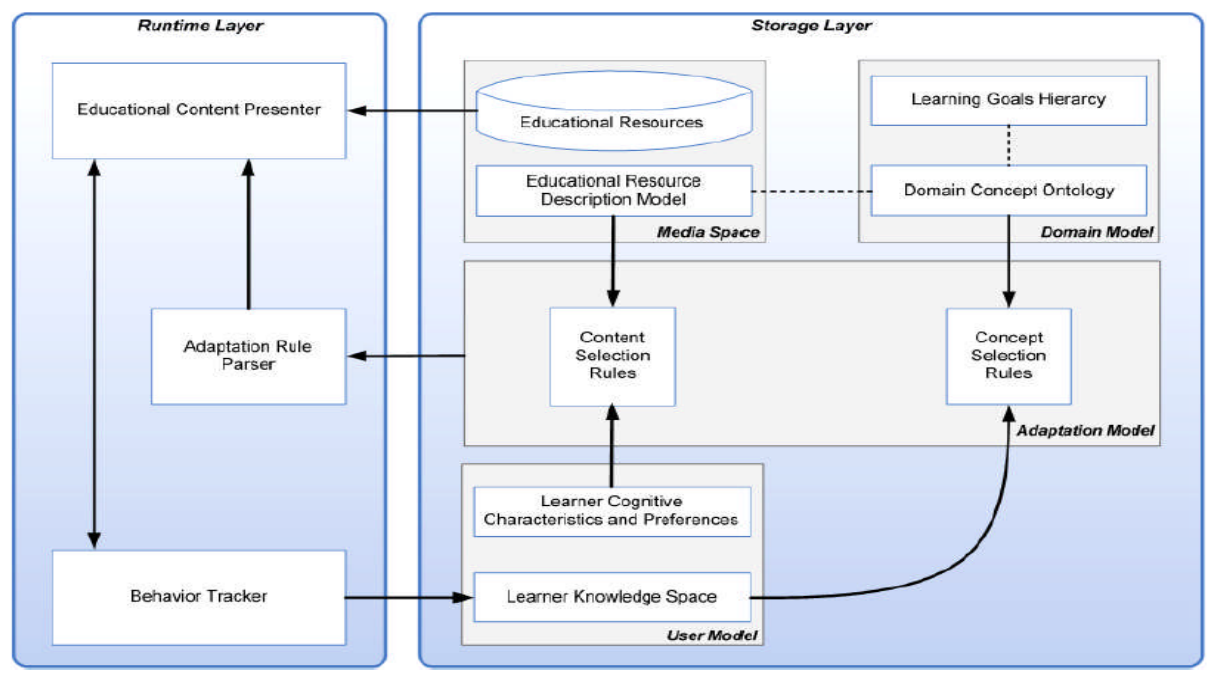

Fig. 5. Architecture of Adaptive Educational systems[19]

- Domain model structure of knowledge domain which is often referred to as a graph. Several researchers intend to build the domain model by using ontologies.

- Media Model contains learning resources and associated descriptive information (metadata).

- Adaptation model is the main component that gives effect to adaptation. It contains content and concepts selection rules. By applying these rules in content selection, it helps us choose the appropriate educational resources from the internal model. On the other hand, the concept selection rules are used to select the appropriate notions of the domain model. These rules must comply with a user model so that the selection becomes correct.

- User Model contains information and data about the user.

\subsection{Integration module}

Including interoperability and reusability characteristics, our diagnostic tool can be integrated into an AES and can improve its adaptation at the level of the learner knowledge level and its learning styles. (figure5) 


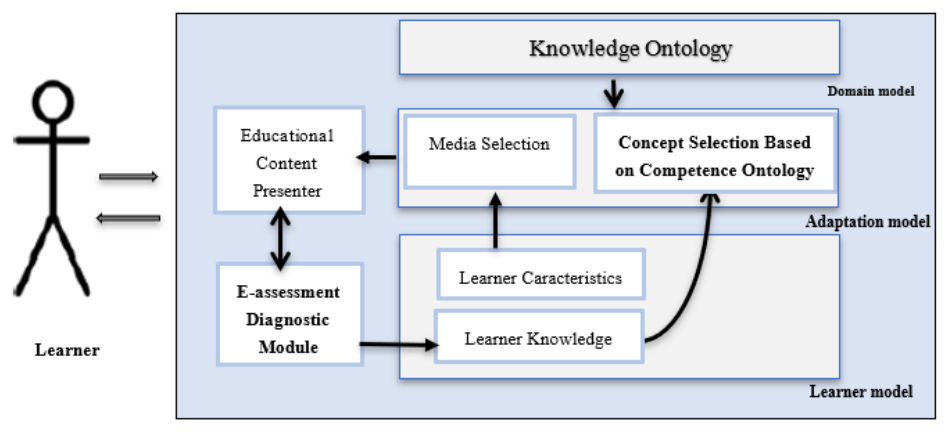

Fig. 6. Integration of our diagnostic module into AHES

\section{$5 \quad$ Conclusion and Further Work}

In a situation of formative evaluation, the specification of learner's source of errors and overcome their in a real time is the key of any adaptation: The adaptation must first take into account the content of the activity to present for the learner and then the way it will be presented (according to his learning style); we present in this article a novel view of assessment which could be exploited into adaptive educational systems and e-learning platforms in general. The proposed tool allows to specify for each learner the adapted content and then the way to present it according to their preferences and their learning styles.

Our working now is focused on the implementation of the tool, as future work, an experiment of our Assessment tool with learners in a real situation in a defined domain.

\section{References}

[1] Park, O., \& Lee, J.( 2004 ). Adaptive instructional systems. In D. H. Jonassen(Ed.), Handbook of research for educational communications and technology (pp. 651-685). Mahwah, NJ: Lawrence Erlbaum.

[2] Conati, C.( 2002 ). Probabilistic assessment of user's emotions in educational games. Journal of Applied Artificial Intelligence, 16 (7-8), 555-575. https://doi.org/10.1080/ 08839510290030390

[3] Sure, V. J., Lajoie, S. P., \& Gluck, K. A.( 2000 ). Individualized and group approaches to training. In S. Tobias\& J. D. Fletcher(Eds.), Training and retraining: A handbook for business, industry, government, and the military (pp. 171-207). New York: Macmillan.

[4] Snow, R. E.( 1989 ). Toward assessment of cognitive and conative structures in learning. Educational Researcher, 18 (9), 8-14. https://doi.org/10.3102/0013189X018009008

[5] Snow, R. E.( 1994 ). Abilities in academic tasks. In R. J. Sternberg \& R. K. Wagner (Eds.), Mind in context: Interactionist perspectives on human intelligence (pp. 3-37). New York: Cambridge University Press.

[6] Brusilovsky, P. (1996). Methods and techniques of adaptive hypermedia. User Modeling and User-adapted Interaction, 6, 87-129. https://doi.org/10.1007/BF00143964 
[7] Brusilovsky, P. (1999) Adaptive and intelligent technologies for Web-based education. In C. Rollinger, \& C. Peylo (Eds.), Special issue on intelligent systems and tele teaching (vol. 4; pp. 19-25).

[8] Brusilovsky. Adaptive Hypermedia. User Modeling and User-Adapted Interaction, vol. 11, no. 1-2 p.p. 87-110, 2001

[9] Hrich, N., Lazaar, M., Khaldi, M., 2015. Proposal of a new approach for supplementary tutoring online. International Journal of Engineering Science and Innovative Technology (IJESIT), 4, 35-40.

[10] Hrich, N., Lazaar, M., Khaldi, M., 2015. Integration of a Diagnostic Module into an Intelligent Tutoring System. International Research Journal of Computer Science (IRJCS), 2, 11-17.

[11] Hrich, N., Lazaar, M., Khaldi, M, 2017. A model for pedagogical supporting based on competencies evaluation and ontologies, International Research Journal of Computer Science (IRJCS)

[12] De Ketele, J. M. (2000). En guise de synthèse: Convergences autour des compétences [Agreements around competence]. In C. Bosman, F. M. Gerard, \& X. Roegiers (Eds.), Quel avenir pour les compétences? [Which future for competences?] (pp. 187-191). Brussels, Belgium: De Boeck Université.

[13] De Ketele, J. M., \& Gerard, F. M. (2005). La validation des épreuves d'évaluation selon l'approche par les compétences [Validation of evaluation tests according to the competence approach]. Mesure et Évaluation en Éducation, 28(3), 1-26

[14] Jonnaert, P., (2002). Compétences et socioconstructivisme-Un cadre théorique [Competences and socioconstructivism - A theoretical frame]. Brussels, Belgium: De Boeck Université.

[15] Le Boterf, G. (1994). De la compétence. Essai sur un attracteur étrange [About competence. Essay about a strange attraction]. Paris: Éditions de l'Organisation.

[16] Perrenoud, P. (1997). Construire des compétences dès l'école [Building competences in schools]. Paris: ESF.

[17] Roegiers, X. (1996). Khoa su pham tích hop, hay làm thê nào dê phàt triên càc nång luc o nhà truòng [The pedagogy of integration, or how to develop competencies at the school]. Hanoi, Vietnam: Nhà Xuât Bán Giáo Duc [Vietnam Education Publishing House].

[18] Xavier Roegiers, L'évaluation selon la pédagogie de l'intégration, 2006.

[19] P. Brusilovsky and E. Millán ( ) User Models for Adaptive Hypermediaand Adaptive Educational Systems

\section{Authors}

Najoua Hrich is withthe Computer lab, operational research, and applied statistics, Abdelmalek Essaadi University, Faculty of Sciences, Tetouan, Morocco (e-mail: amine.najoua@gmail.com).

Mohamed Lazaar is with the Computer lab, operational research, and applied statistics, Abdelmalek Essaadi University, National School of Applied Sciences (ENSA), Tetouan, Morocco (e-mail: Lazaarmed@gmail.com).

MohamedKhaldi is with the Computer lab, operational research, and applied statistics, Abdelmalek Essaadi University, Faculty of Sciences, Tetouan, Morocco (email: medkhaldi@yahoo.fr).

Article submitted 2018-11-16. Resubmitted 2018-12-20. Final acceptance 2018-12-21. Final version published as submitted by the authors. 